\title{
Photosynthetic activity of Triticum dicoccum $\times$ Triticum aestivum alloplasmic lines during vegetation in connection with productivity traits under varying moister conditions
}

\author{
N.V. TERLETSKAYA ${ }^{* * *,+}$ (iD , V.YU. STUPKO ${ }^{* * *,+}$ (iD , N.A. ALTAYEVA ${ }^{* *}$, N.O. KUDRINA ${ }^{*, *}$, \\ I.V. BLAVACHINSKAYA*, M.S. KURMANBAYEVA*, and U. EREZHETOVA*
}

Department of Biodiversity and Biological Resources, Faculty of Biology and Biotechnology al-Farabi Kazakh National University, Almaty, Kazakhstan*

Institute of Plant Biology and Biotechnology, Almaty, Kazakhstan ${ }^{* *}$

Krasnoyarsk Research Institute of Agriculture, Federal Research Center 'Krasnoyarsk Scientific Center'SB RAS,

Krasnoyarsk, Russian Federation ${ }^{* * *}$

Central Laboratory for Biocontrol, Certification and Preclinical Trials, Almaty, Kazakhstan ${ }^{\#}$

\begin{abstract}
Drought is a key stressor under global climate change conditions around the world. Triticum dicoccum Shuebl is a species with high potential drought tolerance. Photosynthesis is the primary physiological process affected by water deficit. Rapid light curves (RLCs), recorded using PAM-fluorometers, appear suitable for drought tolerance determination in breeding material. Chlorophyll fluorescence parameters at different vegetation stages, morphophysiological traits, and their relationship with the productivity were analyzed in nine alloplasmic lines (allolines) of $T$. dicoccum Shuebl $\times T$. aestivum L. partially exposed to drought conditions. Quantum yield parameters at the beginning of RLC at the early vegetation stages correlated with the productivity of investigated lines. Parameters related to photosynthetic capacity had a stronger correlation with the productivity at the stages of subflag and flag formation. For drought tolerance screening, quantum yield of nonorganized energy passive dissipation is particularly promising. Chlorophyll fluorescence and productivity data confirm the potential of the presented breeding strategy in allolines D-d-05 and D-d-05b.
\end{abstract}

Keywords: alloplasmic lines; drought tolerance; photosynthesis; vegetation stage; wheat.

\section{Highlights}

- PSII quantum yields at early vegetation stages can predict the fertility of wheat

- Rapid light curves appeared to be productivity potential indicators

- Allolines of T. dicoccum $\times$ T. aestivum are perspective for drought tolerance induction
Received 23 September 2020

Accepted 11 January 2021

Published online 2 February 2021

${ }^{+}$Corresponding author

e-mail: teni02@mail.ru (N.V. Terletskaya) stupko@list.ru (V.Yu. Stupko)

Abbreviations: $\mathrm{Chl}$ - chlorophyll; ChlFP - chlorophyll fluorescence parameter; $\mathrm{E}_{\mathrm{k}}$ - minimum saturation irradiance; ETR $\mathrm{max}_{\max }-\mathrm{PSII}$ maximum electron transport rate; $F_{m}{ }^{\prime}-$ maximum fluorescence yield of the light-adapted leaf; $F_{t}-$ fluorescence yield just before the

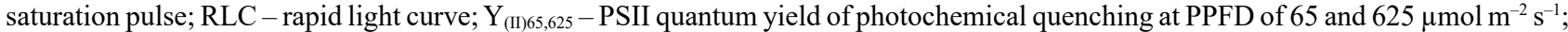
$\mathrm{Y}_{(\mathrm{NO}) 65,625}$ - nonorganized energy passive dissipation in form of heat and fluorescence at PPFD of 65 and $625 \mu \mathrm{mol} \mathrm{m}^{-2} \mathrm{~s}^{-1} ; \mathrm{Y}_{(\mathrm{NPQ}) 65,625}-$ nonphotochemical energy conversion due to downregulation mechanisms at PPFD of 65 and $625 \mu \mathrm{mol} \mathrm{m}^{-2} \mathrm{~s}^{-1} ; \alpha-$ the initial slope of RLC.

Acknowledgements: This research was carried out in the framework of the project AP05131734 'Physiological and molecular genetic features of the functioning of the photosynthetic apparatus of alloplasmic lines of wheat, obtained as a result of interspecific crossings, in connection with their drought resistance' (2018-2020). This grant was funded by the Ministry of Education and Science of the Republic of Kazakhstan.

Conflict of interest: The authors declare that they have no conflict of interest. 


\section{Introduction}

The global trend of average annual temperature rise and general climate aridization primarily affect crop production. Abiotic problems, which plants face, include water stress, salt stress, stress from exposure to high or low temperatures, toxic metals, lack of nutrients, and light stress (Pareek et al. 2010). Among these stressors, water stress is the most common. An important factor, which influences the growth and yield of any plant in arid and semiarid regions, is water availability (Chaves et al. 2009). Understanding how plants respond to drought can play a major role in crop protection under adverse field conditions and productivity stabilization.

A yield decline has been reported in response to water shortages at a reproductive period (Gupta et al. 2001, Inoue et al. 2004, Rajala et al. 2009, Pradhan et al. 2012). There is evidence that drought at tillering, heading, and grainfilling stages is the most harmful to wheat since it brings significant crop loss (Zhao and Running 2009, Saqib et al. 2013). Given that, the moisture deficiency impact on grain productivity at different periods of vegetation remains unclear (Cui et al. 2015, 2019).

Under drought stress, many metabolic processes are negatively affected. Net $\mathrm{CO}_{2}$ assimilation, stomatal conductance, and transpiration decline in response to drought. Photosynthesis is the very first process affected by a shortage of water, long before the signs of water deficit become visible in plants (Ali and Ashraf 2011, Ashraf and Harris 2013, del Pozo et al. 2020).

Changes in plant nutrition, temperature, and water availability affect chlorophyll (Chl) fluorescence parameters indirectly, mainly through changes in the activity of the Calvin-Benson cycle and subsequent variations in the prime metabolism of plants (Flexas et al. 2004, Lawlor and Tezara 2009). It is recognized that water deficit affects the transfer of electrons from water to NADP (Dalal and Tripathy 2018). Operation of reactive centers of welldeveloped seedlings and in mature plants may deteriorate, resulting in a reduced transfer of absorbed light energy from light-harvesting complexes to photodamaged reactive centers. Consequently, it generates a large amount of singlet oxygen through the reactions of photosensitivity of Chl (Tripathy et al. 2007, Miller et al. 2010). The oxygenevolving complex of PSII as well as PSII and PSI reaction centers can be disrupted (He et al. 1995, Giard et al. 1996).

Different fluorescence-based parameters are suggested in the literature for quantum yields of nonphotochemical energy conversion in PSII, $\mathrm{Y}_{(\mathrm{NPQ})}$ and $\mathrm{Y}_{(\mathrm{NO})}$, which are complementary with the quantum yield of photochemical energy conversion, $Y_{\text {(II) }}$ (Klughammer and Schreiber 2008a). As it has been described in Arabidopsis, any plant can protect itself from short-term exposure to stressful conditions employing increasing in nonphotochemical components (Klughammer and Schreiber 2008b). These quantum yields comprehensively describe the fate of excitation energy in PSII and allow deep insights into plant capacity to cope with the excess of excitation energy.

Modern PAM-fluorometers, especially rapid light curves(RLCs), obtained with such devices, allow estimating quickly, in comparison with light-response curve, the speed of electron transport through PSII and the efficiency of their usage in the photosynthesis process (del Pozo et al. 2020). Quantum yield data of PSII at the beginning of RLC demonstrate the current state of photosynthetic apparatus and indicate the level of its probable damage. More detailed information on the PSII regulatory and compensatory mechanisms state is provided by the parameters measured at higher photosynthetic active radiation (PAR) in RLC (Ralph and Gademann 2005, Klughammer and Schreiber 2008b). RLC-derived parameters, such as photosynthetic efficiency $(\alpha)$, minimum saturation irradiance $\left(E_{k}\right)$, and PSII maximum electron transport rate $\left(E R_{\max }\right)$ have been widely used for RLCs comparison and can be considered as physiological indicators of plant stress (Li et al. 2010).

Data of the PSII efficiency obtained based on RLCs of plants exposed to water deficiency may become an excellent diagnostic criterion for the selection of promising forms in breeding programs for drought tolerance and development of the most optimal strategy for growing winter wheat (Triticum aestivum L.). The species with high drought tolerance involved in crosses, as we have done in the present study, can increase the effectiveness of breeding programs. For example, alloplasmic wheat lines were derived from the crossing of the drought-resistant form of $T$. dicoccum var. Araratum (Host.) (Terletskaya et al. 2020a) and T. aestivum. Therefore, this work aimed to identify the potential of studied chlorophyll fluorescence parameters (ChlFP) as indicators of productivity based on the data obtained on winter wheat allolines at different stages of plant development growing under drought conditions.

\section{Materials and methods}

Plant material and growths conditions: Nine alloplasmic wheat lines, derived from the crossing of T. dicoccum var. Araratum (Host.) and T. aestivum, Mironowskaya 808 (M-808) varieties, followed by multi-year selection (F12) held by professor N.A. Khaylenko (D-a-05, D-b-05, D-d-05, D-d-05b, D-f-05, D-n-05, D-40-05, D-41-05, D-42-05), were chosen as material for the study. Plants were grown in the field agrocenosis of the 'Kazakh Research Institute of Agriculture and Crop Production' under natural conditions. Stressful conditions were not created specifically.

Meteorological conditions of winter wheat growing season - March-July 2019 - were characterized by relatively high air temperatures and a significant excess of mean annual rainfall in April and June. Instead, rainfall in March (seedlings), May (stem extension - subflag and flag leaf formation), and July (grain-filling stages) was lower in respect to average rates registered for these periods in the past (text table).

Despite the sufficient water supply at tillering and developed flag leaf stages, the onset of drought conditions was registered at least one week before the day of fluorescence recording; during the measurements, the drought conditions were maintained. 


\begin{tabular}{lllclc}
\hline & March & April & May & June & July \\
\hline Temperature $\left[{ }^{\circ} \mathrm{C}\right]$ & & & & & \\
Actual & 3.4 & 12.8 & 17.0 & 22.3 & 27.2 \\
Long-term average & 8.2 & 11.4 & 16.6 & 21.6 & 23.9 \\
Deviation & +4.8 & +1.4 & +0.4 & +0.7 & +3.3 \\
Amount of precipitation $[\mathrm{mm}]$ & & & & & \\
Actual & 77 & 168 & 39 & 72 & 22 \\
Long-term average & 27 & 105 & 106 & 56 & 45 \\
Deviation & $36 \%$ & $161 \%$ & $37 \%$ & $129 \%$ & $49 \%$ \\
\hline
\end{tabular}

Chl fluorescence determination: Fluorescence-related parameters were estimated by determination of fluorescence levels. RLCs were recorded using Junior-PAM (Heinz Walz, GmbH, Effeltrich, Germany) under actinic illumination of $450 \mathrm{~nm}$ (Terletskaya et al. 2017).

Each time top active leaf was selected $(n=3)$. The region of the middle one-third of a leaf was used for fluorescence measurement since this area has the most homogeneous ChFP(Stupko et al. 2019). All measurements were performed on sunny days from 09:00 to 11:00 h. Leaves were shaded by a clip before the RLC recording start. It is difficult to achieve complete darkness under field conditions (Rascher et al. 2000). The conditions achieved could be considered as quasi-darkness.

For each measurement, the fluorometer provided eight saturation light pulses at 10,000 $\mu$ mol(photon) $\mathrm{m}^{-2} \mathrm{~s}^{-1}$ every $20 \mathrm{~s}$, while actinic light was consecutively raised after each pulse from 0 up to $65,90,125,190$, 285,420 , and $625 \mu \mathrm{mol}$ (photon) $\mathrm{m}^{-2} \mathrm{~s}^{-1}$. The equipment recorded the fluorescence shortly before the saturating pulse $\left(\mathrm{F}_{\mathrm{t}}\right)$ and the minimum $\left(\mathrm{F}_{0}{ }^{\prime}\right)$ and maximum $\left(\mathrm{F}_{\mathrm{m}}{ }^{\prime}\right) \mathrm{Chl}$ fluorescence yield after each pulse during the open state of the PSII reaction center after far-red illumination. In the RLCs, at PPFD of 65 and $625 \mu \mathrm{mol} \mathrm{m}{ }^{-2} \mathrm{~s}^{-1}$, the following parameters were calculated using WinControl-3.29 (Heinz Walz, GmbH, Effeltrich, Germany) software: (1) $\mathrm{Y}_{(\mathrm{III} 65}$ and $\mathrm{Y}_{\text {(II)625: effective photochemical quantum yield of PSII; }}$ (2) $\mathrm{Y}_{(\mathrm{NPQ}) 65}$ and $\mathrm{Y}_{(\mathrm{NPQ}) 625}$ : quantum yield of nonphotochemical energy conversion in PSII due to downregulation of the light-harvesting function; and (3) $\mathrm{Y}_{(\mathrm{NO}) 65}$ and $\mathrm{Y}_{(\mathrm{NO}) 625}$ : quantum yield of nonphotochemical energy conversion in PSII other than that caused by downregulation of the lightharvesting function; and (4) PSII electron transport (ETR).

The following equations were used for quantum yield calculation:

$\mathrm{Y}_{(\mathrm{II})}=\left(\mathrm{F}_{\mathrm{m}}{ }^{\prime}-\mathrm{F}_{\mathrm{t}}\right) / \mathrm{F}_{\mathrm{m}}{ }^{\prime}$

$\mathrm{Y}_{(\mathrm{NPQ})}=\left(\mathrm{F}_{\mathrm{t}} / \mathrm{F}_{\mathrm{m}}{ }^{\prime}\right)-\left(\mathrm{F}_{\mathrm{t}} / \mathrm{F}_{\mathrm{m}}\right)$

$\mathrm{Y}_{(\mathrm{NO})}=1-\mathrm{Y}_{(\mathrm{II})}-\mathrm{Y}_{(\mathrm{NPQ})}$

PSII maximum electron transport, as well as initial slope of RLC $(\alpha)$ and $E_{k}$ (PAR value at the intersection of alpha and $\mathrm{ETR}_{\max }$ ), were calculated on the base of RLCs data as described by Ralph and Gademann (2005). These parameters were used for the quantitative comparison of RLCs.
Leaf area determination: The leaf area was determined by the weighting method. Paper-cut leaf contours were weighed on an analytical balance. The leaf area was estimated by equation:

$\mathrm{S}=(\mathrm{a} \times \mathrm{C}) \times \mathrm{b}^{-1}$

where $\mathrm{a}-\mathrm{a}$ mass of paper-cut leaf contour [g], $\mathrm{b}-\mathrm{a}$ mass of standard square of paper [g], C - the area of paper square $\left[\mathrm{cm}^{2}\right]$.

Features of grain productivity determination: The grain yield was determined on the plots of $1 \mathrm{~m}^{2}$. Bundles for certification were collected before harvesting on 25 July. Twenty-five plants were taken from each plot diagonally. The analysis of crop structure and grain productivity was carried out under laboratory conditions. Spike length, the number of spikelets, florets, and grains per spike, the grain forming level, the kernel mass per spike, and the 1,000-grain mass were recorded.

Data analysis: The Student's $t$-test was used to analyze the differences between the samples (Statistica 12, StatSoft Inc., Tulsa, USA). Relationships between ChlFP and productivity traits were determined by Pearson's correlations. For quantum yields and RLCs parameters, the analysis of variance ( $A N O V A$ ) was performed using a wheat form and phenological stage as fixed factors. The factor's significant influence is described in the paper for analyses with Levene's test for homogeneity of variances for $p$-level higher than 0.05 . Plus/minus signs in the tables show the standard error of the mean value. Graphs present mean values with standard error bars. Marks * and ** indicate the reliability of results at 0.05 and 0.01 significance level, respectively (unless otherwise is pointed out).

\section{Results}

Photosynthetic activity of alloplasmic lines: Since it is important to study the relationship of photosynthesis with respect to morphophysiological growth parameters, as well as the grain productivity of wheat, "photosynthetic behavior' of studied species and alloplasmic lines was analyzed during the growing season from April to July. It was shown that the vegetation stage and leaf development stage are important factors affecting the intensity of photosynthesis, which changes during the growing season. 
The $\mathrm{Y}_{(\mathrm{NPQ}) 625}$ was noticeably reduced at the stages of flag leaf forming and mature flag leaf $(F=29.10, d f=4$, $p<0.001, \eta^{2}=0.42$ for factor growth stage) (Fig. 1). $\mathrm{Y}_{(\mathrm{II}) 625}$ had the lowest values at subflag forming stage $\left(\eta^{2}=0.41\right.$ for factor growth stage, $p<0.001)$. There was a significant decrease in $\mathrm{Y}_{(\mathrm{NO}) 625}$ at the stem extension stage (Fig. 1), along with $\mathrm{ETR}_{\max }$ and $\mathrm{E}_{\mathrm{k}}$ (Fig. 2). Low values of $\mathrm{ETR}_{\max }$, $\alpha$, and $E_{k}$ are common characteristics of the subflag developmental stage.

The effective quantum yield at PPFD of $625 \mu \mathrm{mol}$ $\mathrm{m}^{-2} \mathrm{~s}^{-1}$ was largely dependent on the form of the investigated sample $(F=3.02, d f=10, p<0.01)$. The same can be said about $\mathrm{Y}_{(\mathrm{NPQ}) 625}(F=3.62, d f=10, p<0.01$ for factor form) (Fig. 3). D-f-05 and D-a-05 showed low values of $\mathrm{Y}_{(\mathrm{II}) 625}$ throughout vegetation. They had fairly high $\mathrm{Y}_{(\mathrm{NPQ}) 625}$, as well as D-b-05 did. In contrast, $T$. dicoccum and M-808, which showed low $\mathrm{Y}_{(\mathrm{NPQ}) 625}$, had mean values of $\mathrm{Y}_{(\mathrm{II}) 625}$.

Some lines were distinguished by a number of parameters at various growth stages (Table 1). For instance, at the tillering stage, low values of $\mathrm{Y}_{\text {(II)65 }}, \mathrm{Y}_{\text {(II)625 }}$ (Table 1; Fig. 1S, supplement), ETR $\max _{\max } \mathrm{E}_{\mathrm{k}}$ (Table 1; Fig. 2S $A, B$, supplement) were recorded for D-f-05, against the background of high $\mathrm{Y}_{(\mathrm{NPQ}) 625}$.

The highest levels for five of the tested parameters were determined for variety M-808 along with low values of $\mathrm{Y}_{(\mathrm{NPQ})}$ (Table 1). D-d-05 line differed from half of the studied forms by high values of $\mathrm{Y}_{(\mathrm{II}) 625}$ and electron transport rate parameters (Table 1, Figs. 1S, 2S). $\mathrm{Y}_{(\mathrm{NO}) 65}$ values positively correlated with the number of florets per spike $\left(r=0.61^{*}\right)$ at the tillering stage (Table $1 \mathrm{~S}$, supplement).

Minimum variation of quantum yield indicators at the beginning of RLC between studied forms at stem extension stage was noted (Fig. 1S). The alloline D-b-05 was characterized by a minimum value of $\mathrm{Y}_{(\mathrm{II}) 625}$ (Table 1 , Fig. 1S) and a high $\mathrm{Y}_{(\mathrm{NPQ}) 625}$ (Table 1, Fig. 1S) and $\alpha$ (Table 1, Fig. 2SC). The alloline D-a-05 differed from half of the forms by high $\mathrm{Y}_{(\mathrm{NPQ}) 65}$ and by low $\mathrm{ETR}_{\max }$ and

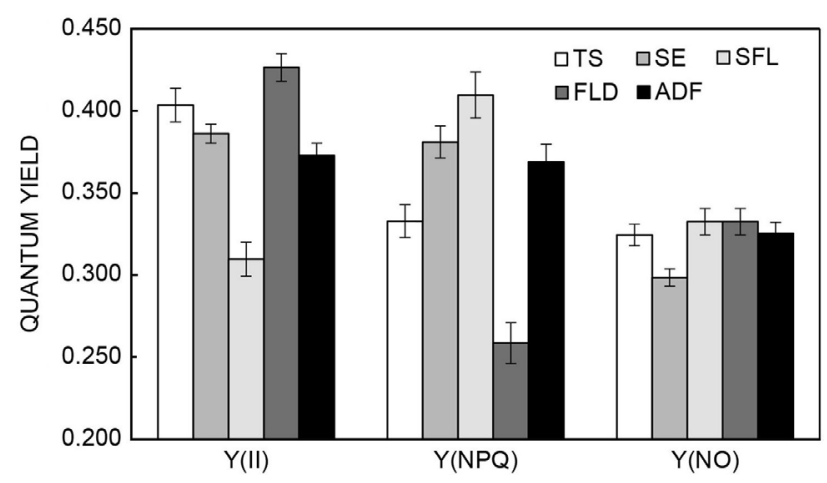

Fig. 1. Mean values of PSII quantum yield of photochemical quenching $\left(\mathrm{Y}_{(\mathrm{II})}\right)$, nonphotochemical energy conversion due to downregulation mechanisms $\left(\mathrm{Y}_{(\mathrm{NPQ})}\right)$, and nonorganized energy passive dissipation in form of heat and fluorescence $\left(\mathrm{Y}_{(\mathrm{NO})}\right)$ in the rapid light curves at PPFD of $625 \mu \mathrm{mol} \mathrm{m}^{-2} \mathrm{~s}^{-1}$ at different vegetation stages. Values are means $\pm \mathrm{SE}$. TS - tillering stage; SE - stem extension; SFL - subflag leaf; FLD - flag-leaf development stage; ADF - anthesis, developed leaf.
$\mathrm{E}_{\mathrm{k}}$ (Table 1). The line D-40-05 was characterized by high $\mathrm{Y}_{(\mathrm{NPQ}) 65}$. T. dicoccum demonstrated high values of $\mathrm{Y}_{(\mathrm{II}) 625}$ and $E_{k}$ and low $\alpha$. The alloline D-42-05 differed from half of the studied forms by low $\mathrm{ETR}_{\max }$ and $\mathrm{E}_{\mathrm{k}}$. For D-n-05 alloline, high $\mathrm{Y}_{(\mathrm{NO}) 65}$ was recorded.

The number of spikelets per spike negatively correlated with $\mathrm{Y}_{(\mathrm{NPQ}) 65}\left(r=-0.61^{*}\right)$ at the stem-extension stage and positively correlated with $\mathrm{Y}_{(\mathrm{III}) 65}\left(r=0.67^{*}\right)$. The latter parameter, as well as $\alpha$, also showed a direct correlation with grain forming $\left(r=0.64^{*}\right)$ (Table 1S).

The line D-n-05 in terms of $\mathrm{Y}_{(\mathrm{II}) 625}$ at the subflag stage was lower in confront to most genotypes and had values similar to M-808 and D-b-05 (Table 1). The latter showed high $\mathrm{Y}_{(\mathrm{NPQ}) 625}$ values and low $\mathrm{ETR}_{\max }$ (Figs. 1S, 2S). The D-42-05 was characterized by low $\mathrm{ETR}_{\max }$. T. dicoccum was distinguished by high values of $\mathrm{Y}_{(\mathrm{II} 625}, \mathrm{ETR}_{\max }$, and $\mathrm{E}_{\mathrm{k}}$ and had low $\mathrm{Y}_{(\mathrm{NPQ}) 625}$ at this stage (Table 1, Fig. 1S). Line D-d-05b had low $\mathrm{Y}_{(\mathrm{NO}) 65}$ (Fig. 1S). Many ChFP at this

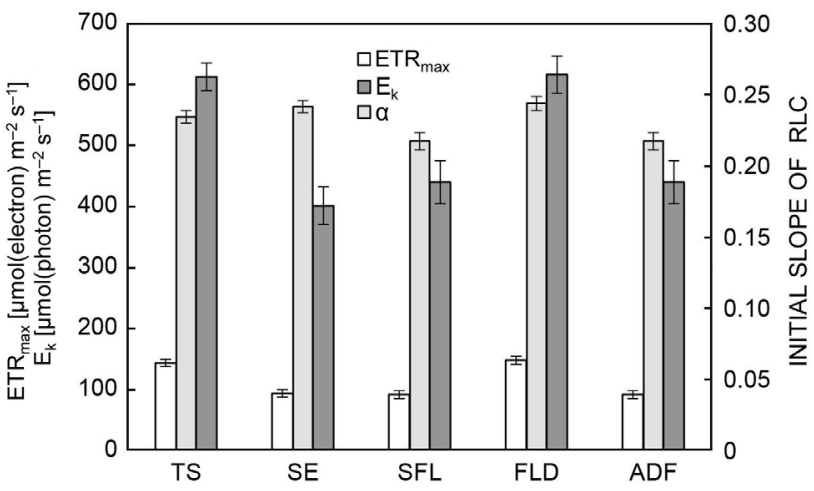

Fig. 2. Mean values of photosynthetic capacity parameters at different vegetation stages. Values are means \pm SE. TS - tillering stage; SE - stem extension; SFL - subflag leaf; FLD - flag-leaf development stage; ADF - anthesis, developed leaf; $\alpha$ - initial slope of rapid light curve; ETR max $_{\text {m }}$ PSII maximum electron transport rate; $\mathrm{E}_{\mathrm{k}}$ - minimum saturation irradiance, $\mathrm{RLC}$ - rapid light curve.

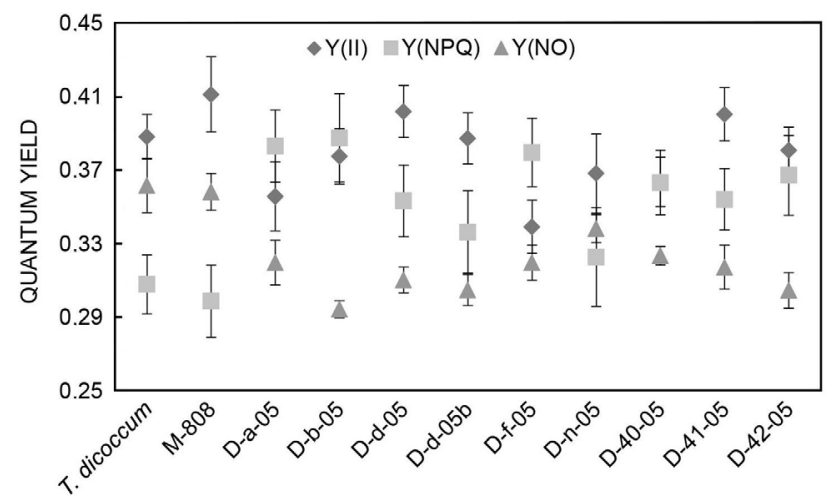

Fig. 3. Mean values of PSII quantum yield of photochemical quenching $\left(\mathrm{Y}_{(\mathrm{II})}\right)$, nonphotochemical energy conversion due to downregulation mechanisms $\left(\mathrm{Y}_{(\mathrm{NPQ})}\right)$, and nonorganized energy passive dissipation in form of heat and fluorescence $\left(\mathrm{Y}_{(\mathrm{NO})}\right)$ in the rapid light curves at PPFD of $625 \mu \mathrm{mol} \mathrm{m}^{-2} \mathrm{~s}^{-1}$ of different wheat genotypes. Values are means $\pm \mathrm{SE}$. 
Table 1. Species and interspecific hybrids (allolines) of winter wheat photosynthetic activity data $t$-test comparison results. $\alpha-$ initial slope of rapid light curve; ETR $_{\max }$ - PSII maximum electron transport rate; $\mathrm{E}_{\mathrm{k}}$ - minimum saturation irradiance; High - parameter value of genotype is lower than mean value; Low - parameter value of genotype is lower than mean value; $\mathrm{Y}_{\text {(II)65, }} \mathrm{Y}_{\text {(II)625 }}$ - effective photochemical quantum yield of PSII; $\mathrm{Y}_{(\mathrm{NPQ}) 65}, \mathrm{Y}_{(\mathrm{NPQ}) 625}$ - quantum yield of nonphotochemical energy conversion in PSII due to downregulation of the light-harvesting function; $\mathrm{Y}_{(\mathrm{NO}) 65}, \mathrm{Y}_{(\mathrm{NO}) 625}$ - quantum yield of nonphotochemical energy conversion in PSII other than that caused by downregulation of the light-harvesting function at PPFD of 65 and $625 \mu \mathrm{mol} \mathrm{m}^{-2} \mathrm{~s}^{-1}$ at rapid light curve; ChlFP - chlorophyll fluorescence parameter. * - indicate significant differences at $p \leq 0.05$ of marked genotype from the half of investigated genotypes, $* *$ - indicate significant differences at $p \leq 0.05$ of marked genotype from the majority of investigated genotypes according to $t$-test results.

\begin{tabular}{|c|c|c|c|c|c|c|}
\hline \multirow{2}{*}{$\begin{array}{l}\text { Photosynthetic } \\
\text { parameter }\end{array}$} & \multirow{2}{*}{$\begin{array}{l}\text { ChlFP } \\
\text { value }\end{array}$} & \multicolumn{5}{|c|}{ Vegetation stage } \\
\hline & & Tillering & Stem extension & Subflag leaf & $\begin{array}{l}\text { Flag-leaf } \\
\text { formation }\end{array}$ & $\begin{array}{l}\text { Anthesis, } \\
\text { developed flag leaf }\end{array}$ \\
\hline \multirow[t]{2}{*}{$\mathrm{Y}_{(\mathrm{III} 65}$} & Low & D-f- $05^{*}$ & - & - & - & D-f- $05^{* *}$ \\
\hline & High & T. dicoccum ${ }^{*}$ & - & - & D-d- $05 b^{* *}$ & $\begin{array}{l}\text { D-42-05*, } \\
\text { D- } 41-05^{*}\end{array}$ \\
\hline \multirow[t]{2}{*}{$\mathrm{Y}_{(\mathrm{NPQ}) 65}$} & Low & - & - & - & - & - \\
\hline & High & D-a- $05^{*}$ & $\begin{array}{l}\text { D- } 40-05^{*} \\
\text { D-a- } 05^{*}\end{array}$ & - & - & D- $42-05^{* *}$ \\
\hline \multirow[t]{2}{*}{$\mathrm{Y}_{(\mathrm{NO}) 65}$} & Low & - & - & D-d-05b* & D-d-05b ${ }^{* *}$ & $\begin{array}{l}\text { D-a- } 05^{*} \\
\text { D-42-05* } \\
\text { D-41-05* }\end{array}$ \\
\hline & High & - & $\begin{array}{l}\text { D-d- } 05 b^{*} \\
\text { D-n- } 05^{*}\end{array}$ & D- $40-05^{*}$ & - & D-f- $05^{*}$ \\
\hline \multirow[t]{2}{*}{$Y_{(I I) 625}$} & Low & D-f- $05^{*}$ & D-b- $05^{*}$ & D-n- $05^{* *}$ & - & D-a- $05^{*}$ \\
\hline & High & $\begin{array}{l}\text { M- } 808^{*} \\
\text { D-d- } 05^{*}\end{array}$ & - & T. dicoccum ${ }^{* *}$ & - & - \\
\hline \multirow{2}{*}{$\mathrm{Y}_{(\mathrm{NPQ}) 625}$} & Low & M- $808^{* *}$ & - & T. dicoccum ${ }^{* *}$ & - & - \\
\hline & High & D-f- $05^{*}$ & D-b- $05^{*}$ & D-b- $05^{*}$ & - & $\mathrm{D}-\mathrm{a}-05^{*}$ \\
\hline \multirow{2}{*}{$\mathrm{Y}_{(\mathrm{NO}) 625}$} & Low & - & - & D-40-05 & - & - \\
\hline & High & M- $808^{*}$ & - & M- $808^{*}$ & - & $\begin{array}{l}\text { T. dicoccum } \\
\text { D-d-05b }\end{array}$ \\
\hline \multirow[t]{2}{*}{$\mathrm{ETR}_{\max }$} & Low & D-f- $05^{* *}$ & $\begin{array}{l}\text { D-a- } 05^{* *} \\
\text { D- } 42-05^{*}\end{array}$ & $\begin{array}{l}\text { D- } 42-05^{*} \\
\text { D-b- } 05^{*}\end{array}$ & - & $\begin{array}{l}\text { D-a- } 05^{* *} \\
\text { D- } 42-05^{* *}\end{array}$ \\
\hline & High & $\begin{array}{l}\text { M- } 808^{*} \\
\text { D-d- } 05^{*}\end{array}$ & - & T. dicoccum ${ }^{* *}$ & $\begin{array}{l}\text { D- } 42-05^{*} \\
\text { D-b- } 05^{*}\end{array}$ & $\begin{array}{l}\text { M-808*, } \\
\text { T. dicoccum }\end{array}$ \\
\hline \multirow[t]{2}{*}{$\alpha$} & Low & - & - & - & - & - \\
\hline & High & - & D-b- $05^{*}$ & - & - & - \\
\hline \multirow[t]{2}{*}{$\mathrm{E}_{\mathrm{k}}$} & Low & D-f- $05^{*}$ & $\begin{array}{l}\text { D-a- } 05^{* *} \\
\text { D- } 42-05^{*}\end{array}$ & - & - & $\begin{array}{l}\text { D-a- } 05^{* *} \\
\text { D- } 42-05^{* *}\end{array}$ \\
\hline & High & - & T. dicoccum ${ }^{*}$ & T. dicoccum $^{* *}$ & D-b- $05^{*}$ & $\begin{array}{l}\text { M- } 808^{*}, \\
\text { T. dicoccum }\end{array}$ \\
\hline
\end{tabular}

stage correlated with the number of spikelets per spike (Table 1S). Direct correlation was observed for $\mathrm{Y}_{(\mathrm{II}) 625}$ $\left(r=0.61^{*}\right), \mathrm{Y}_{(\mathrm{NO}) 625}\left(r=0.74^{* *}\right), \mathrm{ETR}_{\max }\left(r=0.80^{* *}\right)$, and $\mathrm{E}_{\mathrm{k}}$ $\left(r=0.78^{* *}\right)$. The parameters $\mathrm{Y}_{(\mathrm{NPQ})}$ and 'spikelets per spike' had an opposite correlation $\left(r=-0.80^{* *}\right)$.

For all forms, except $T$. dicoccum, $\mathrm{Y}_{\text {(II)625 }}$ average values increase was fixed, the variability of this parameter between genotypes decreased at the flag-formation stage (coefficient of variation, $\mathrm{CV}=10.1 \%$ ). High $\mathrm{ETR}_{\max }$ and $E_{k}$ were typical for alloline D-b-05, which differed in these parameters from half of the lines tested (Table 1). Also, high $\mathrm{ETR}_{\max }$ was observed for D-42-05. Alloline D-d-05b was characterized by the highest values of $\mathrm{Y}_{(\mathrm{II}) 65}$ and lowest values of $\mathrm{Y}_{(\mathrm{NO}) 65}$ (Figs. 3A, 1S). Quantity of spikelets per spike was inversely proportional to $\mathrm{Y}_{\text {(II)625 }}\left(r=-0.78^{* *}\right)$,
$\operatorname{ETR}_{\max }\left(r=-0.74^{* *}\right)$, and $\alpha\left(r=-0.70^{* *}\right)$ at this stage. A similar relationship was noted for grain forming and $\mathrm{Y}_{(\mathrm{NO}) 625}\left(r=-0.66^{*}\right)$. In turn, $\mathrm{E}_{\mathrm{k}}$ under these conditions negatively correlated with the quantity of florets per spike $\left(r=-0.77^{* *}\right)$ (Table 1S).

D-a-05 was characterized by low values for many parameters $\left(\mathrm{E}_{\mathrm{k}}, \mathrm{ETR}_{\max }, \mathrm{Y}_{(\mathrm{II}) 625}, \mathrm{Y}_{(\mathrm{NO}) 65}\right)$ (Table 1, Figs. 3A, 1S; $2 \mathrm{~S} A, B)$ and by high $\mathrm{Y}_{(\mathrm{NPQ}) 625}$ (Fig. 1S) at developed flag-leaf stage. The low $\mathrm{Y}_{(\mathrm{II}) 65}$ and, in contrast, high values of $\mathrm{Y}_{(\mathrm{NO}) 65}$ were demonstrated by D-f-05. D-41-05 and D-42-05 had an inverse ratio of these parameters. D-42-05 also had high $\mathrm{Y}_{(\mathrm{NPQ}) 65}$ (Fig. 1S). At the same time, this alloline had very low ETR $\mathrm{Eax}_{\text {ax }}$ and $\mathrm{E}_{\mathrm{k}}$ indicators (Table 1; Fig. 2S $A, B)$. M-808 and T. dicoccum were characterized by high $\mathrm{ETR}_{\max }$ and $\mathrm{E}_{\mathrm{k}}$ values, with high $\mathrm{Y}_{(\mathrm{NO}) 625}$ for 
T. dicoccum. These parameters in D-d-05b were similar to T. dicoccum.

The quantum yield of nonphotochemical energy conversion in PSII, other than caused by downregulation of light-harvesting function at PPFD of 65 and $625 \mu \mathrm{mol}$ $\mathrm{m}^{-2} \mathrm{~s}^{-1}$, was inversely proportional to grain forming $\left(r_{65}=-0.62^{*}, r_{625}=-0.66^{*}\right)$. The latter parameter also correlated positively with $\mathrm{Y}_{(\mathrm{II}) 65}$ and $\alpha$ (Table 1S).

Grain productivity: The parameters related to grain productivity of wheat in the field are presented in Table 2. As follows from these data, the low variation of almost all wheat types and allolines characters under the conditions of the 2019 year were the following: 'plant height', 'length of the main spike', 'number of spikelets', and 'number of flowers in the main spike'.

A high coefficient of variation for such attributes as 'productive bushiness', 'number of flowers per spike', and 'grain mass from the main spike' for individual allolines can indicate both potential possibilities and instability of the gene system responsible for this trait in these hybrid forms.

In terms of productivity, alloline D-d-05 was the most successful. It was characterized by high average values for the majority of parameters, especially in terms of 1,000-grain mass, the mass of the spike, grain forming, and mass of the grain per spike. Alloline D-d-05b had similar values. The lowest 'grain forming' and 'kernel mass per spike' were measured for the alloline D-f- 05 .

The area of leaves of upper tiers: Differences between studied species were revealed by leaf area of upper tiers measured under the field conditions. As follows from Fig. 4, the smallest area of flag leaf was observed for the alloline D-41-05 $\left(18.5 \mathrm{~cm}^{2}\right)$. The largest one was observed for alloline D-d-05b $\left(38.7 \mathrm{~cm}^{2}\right)$. The smallest subflag leaf area was found for D-b-05 alloline $\left(27.8 \mathrm{~cm}^{2}\right)$, the largest for D-d-05b alloline $\left(40.8 \mathrm{~cm}^{2}\right)$. Values of these indicators of euplasmic parental forms were 22.8 and $24.4 \mathrm{~cm}^{2}$ (flag leaf) and 33.8 and $43.6 \mathrm{~cm}^{2}$ (subflag leaf) for T. dicoccum and T. aestivum, respectively. At the same time, the largest ratio of flag/subflag areas was registered for allolines D-a-05, D-d-05b, D-d-05, and D-b-05 (Fig. 5). Significant correlations were found between the area of flag leaf and the mass of 1,000 grains $\left(r=0.8^{* *}\right)$, the area of subflag leaf and the mass of 1,000 grains $\left(r=0.5^{*}\right)$, and the ratio of the area of flag and subflag leaves and mass of 1,000 grains $\left(r=0.5^{*}\right)$.

\section{Discussion}

Predictably, the increase in the yield of wheat will depend on breeding. Progress in breeding for grain potential is more effective if designed characteristics are targeted (Mohammadi et al. 2009, Fischer and Edmeades 2010). Results of accurate phenotype test performed in the most objective and accessible way in the field conditions allow to determine the right assumptions on the role of photosynthetic performance in the formation of grain productivity and its application in plant breeding. 
Selection of phenotypic traits to assess the effectiveness of plants in water implementation, the formation of optimal architecture and characteristics associated with delayed leaf senescence, remobilization of carbohydrates, Chl content, etc., are considered to be the most useful to improve the yield (Gahlaut et al. 2016).

Earlier, we evaluated these allolines and their parental forms under laboratory conditions on artificially created stress backgrounds (Terletskaya et al. 2020b). This allowed us to differentiate lines by their photosynthetic activity and drought resistance in conditions of severe water deficiency.

The assessment of photosynthetic activity at different stages of plant development under the field conditions allowed, on the one hand, to evaluate the reaction of individually studied allolines to growth conditions and, on the other hand, to determine the main indicators applicable for field screening of both, potentially drought-resistant and productive forms of winter wheat.

Alloline D-f-05, characterized as the least productive by the totality of all indicators, but especially by 'grains per spike' and 'grain forming', showed also low values of $\mathrm{Y}_{\text {(II)65 }}$ under conditions of moisture deficiency (at tillering and developed flag-leaf stages). Low quantum yield parameters at the beginning of RLC indicated damages in the operation of PSII (Klughammer and Schreiber 2008 b), which probably were critical for the plants and characterized the line as drought sensitive.

The graininess of the spike is primarily determined

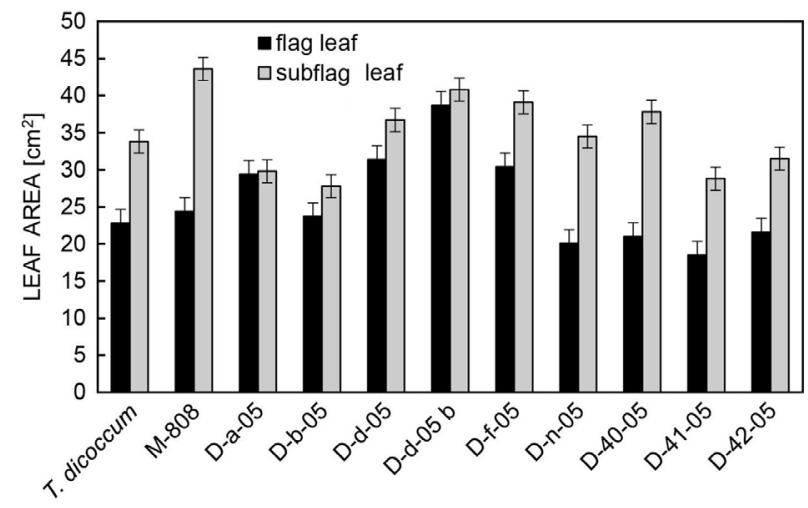

Fig. 4. Comparative characteristics of the leaf area of the upper tiers in species and interspecific hybrids of wheat in the field. Values are means $\pm \mathrm{SE}$. by the number of spikelets formed on the protrusions of the spike. The more spikelets are there, the more grains are in the spike and the more mass of grain is from one spike. Increasing the assimilation capacity of a spike during selection leads to an increase in yield as long as photosynthetic potential allows. However, some imbalance is possible between the genetically specified number of reproductive organs in varieties and hybrids and the possibility of their full formation, resulting in a fall of reproductive organs, lax ear, incomplete maturation (El-Hendawy et al. 2009). Correlation of quantum yield parameters with 'number of florets per spike' and level of 'grain forming' was revealed at PPFD of $65 \mu \mathrm{mol} \mathrm{m} \mathrm{m}^{-2} \mathrm{~s}^{-1}$. Therefore, despite no genotype stood out by $\mathrm{Y}_{\text {(II)65 }}$ and $\mathrm{Y}_{(\mathrm{NPQ}) 65}$, for example, at the stem extension stage, these parameters can predict further productivity. In conditions of insufficient humidification (tillering stage), the negative correlation of $\mathrm{Y}_{(\mathrm{NO}) 65}$ with florets per spike indicates also the importance of determining this component of the quantum output of PSII for the detection of plants sensitive to drought at the initial stages of ontogenesis.

Already at the stages of subflag and flag leaf formation, the 'number of spikelets per spike' and 'grain forming' were correlated with parameters that directly characterize the efficiency of photoprotective reaction $\left(\mathrm{Y}_{(\mathrm{NPQ}) 625}\right)$. Also, they indirectly reflect PSII efficiency, in the case of $E_{k}$, which is related to quenching, indicating the level of PPFD at which nonphotochemical quenching starts to dominate the photochemical one. The maintaining of the high level of photosynthetic activity, which is reflected by high $\mathrm{Y}_{(\mathrm{II}) 625}, \mathrm{ETR}_{\max }$, and low $\alpha$, came to the fore at later stages of development.

It was not possible to determine the maximum quantum yield in this experiment due to the inability to achieve the complete darkness necessary for dark adaptation, however, $\alpha$ could be used as a proxy of this parameter (Ralph and Gademann 2005). The average increase of the abovementioned parameters at the flag formation stage and their negative correlations with the number of spikelets $\left(\mathrm{Y}_{(\mathrm{II}) 625}\right.$, $\left.\mathrm{ETR}_{\max }, \alpha\right)$ and flowers $\left(\mathrm{E}_{\mathrm{k}}\right)$ per spike was observed.

It was described that under water stress higher net photosynthetic rate in flag leaf is maintained by more drought-resistant forms as compared with droughtsensitive wheat forms (Rajala et al. 2009). The level of water consumption during meiosis in the microsporangia of anther and pollen formation is critical in cereals. Thus,

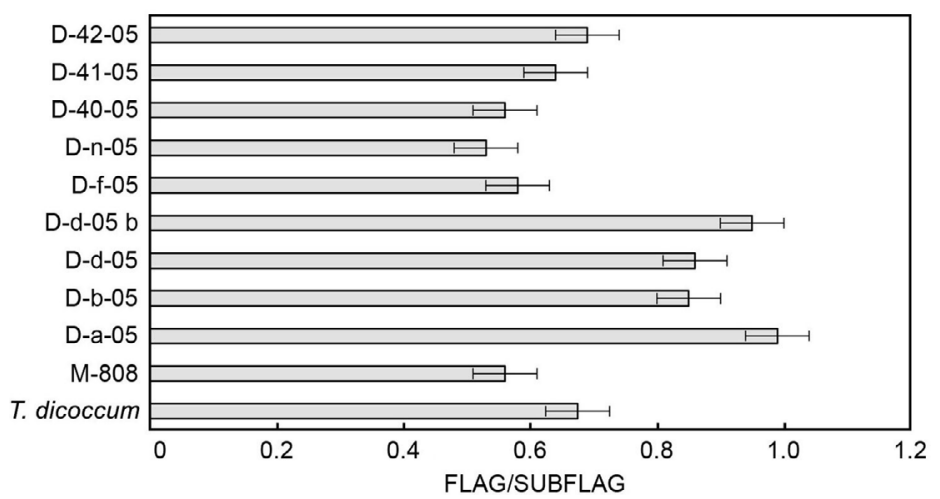

Fig. 5. Comparative characteristics of the ratio of the area of flag and subflag leaves of wheat species and interspecific hybrids under the field conditions. Values are means \pm SE. 
under conditions of insufficient water supply, a significant decrease of grain cereal pollen viability is shown as one of the pronounced nonspecific reactions (Terletskaya et al. 2014). Since the spike initiation occurs at an earlier stage, it is predictable that positive correlations between ChFP ( $\mathrm{Y}_{\text {(II)625 }}, \mathrm{ETR}_{\max }$, and $\mathrm{E}_{\mathrm{k}}$ ) and the number of spikelets were marked at the subflag stage. Meanwhile, the noted ratio between $\mathrm{Y}_{(\mathrm{NO}) 625}$ and 'grain forming' at the flag-formation stage indicates the high proportion of nonorganized NPQ in the studied genotype at this stage and low efficiency of germ formation. In favor of the importance of this quantum yield indicator, high values of the negative correlation of $\mathrm{Y}_{(\mathrm{NO})}$ and positive $\mathrm{Y}_{\text {(II)625 }}$ with the grain forming at the developed flag-leaf stage were observed.

It was also noted that after the photosynthetic apparatus of flag leaf is fully installed (leaf is fully formed), its photosynthetic ability tends to decrease, which is also consistent with the literature (Schöttler et al. 2004). In this work a significant $(p<0.01)$ reduction of photosynthetic capacity reflected by $\mathrm{ETR}_{\max }$ and $\mathrm{E}_{\mathrm{k}}$ of developed flag leaf in comparison to flag-leaf formation stage was demonstrated. The flag leaf usually contributes most with the photosynthates to the grain. Nearly $60 \%$ of the grain saccharides are derived from photosynthates of the flag leaf (Inoue et al. 2004). The absence of any correlation in our data with the parameters reflecting the last phase of plant development (grain-filling stage) could be associated with a large influence on the productivity of the final area of flag leaf and subflag and their photosynthetic efficiency after the $50^{\text {th }}$ stage by Lancashire (Lancashire et al. 1991), where an excess of mean annual rainfall was detected. Cui et al. (2015) also showed that increased photosynthetic activity did not guarantee a sufficient supply of carbohydrates and that the effective leaf area is also a limiting factor for grain filling.

Flag leaf makes up approximately $75 \%$ of the effective leaf area that contributes to grain filling. For this reason, protecting flag leaf is critical for the achievement of the desired yield goals. This is the stage where the highest potential yield, measured by the number of potential fertile florets per spikelet, occurs. However, many of these florets are aborted as a result of main water and nutritional stresses (Cui et al. 2015). Stress from drought during movement and flowering can decline pollen viability and, thus, reduce the number of grains that are forming. Therefore, water shortage at this stage can adversely affect the grain productivity of plants.

Structural transformations in leaves at different stages of plant ontogenesis are described as changes in the direction of strengthening xeromorphic (Inoue et al. 2004). The last, so-called flag leaf can give in length, area, and density of pubescence towards the others. The study of Cui et al. $(2015,2019)$ showed that the effective area of a leaf can also be a limiting factor for grain filling. Without doubts, an insufficient amount of precipitation in June 2019 impacted the formation and development of subflag and flag leaves. Important drought adaptive measure is also considered to be the ratio of flag/subflag leaves that is directly associated with preservation of functional ability of subflag leaf and the degree of development of flag leaf in the period of grain formation. Thus, reducing the area of upper leaves in dry conditions can serve as a major factor limiting grain yield. High correlation values found in the experiment, suggest that a large area of leaves of upper tier provides greater pulling power for the transfer of photosynthetic assimilation from leaf plates to forming grain and confirms the importance of these parameters in full breeding material.

Comparative analysis of the ChFP of the studied forms measured in different phases of ontogenesis made it possible to identify several specific features of their photosystem functioning. So, despite general low values measured for indicators of photosynthetic capacity of D-f-05, this genotype showed high stability of NPQgenerating reactions connected to the generation of a trans-thylakoidal $\Delta \mathrm{pH}$. During RLC recording, a high $\mathrm{Y}_{(\mathrm{NPQ})}$ may compensate for some decrease in $\mathrm{Y}_{(\mathrm{II})}$ and even result in a decrease in $\mathrm{Y}_{(\mathrm{NO})}$ (Klughammer and Schreiber 2008a). Concerning the high efficiency of mechanisms of photoprotection, allolines D-a-05 and D-b-05, which had fairly high productivity, are also of interest.

Parental forms of $T$. dicoccum and M-808 were characterized by high photosynthetic capacity $\left(\mathrm{ETR}_{\max }\right.$, $E_{k}$ ) under drought. However, the functioning of their photoprotection systems was less efficient than that in allolines described above. This was expressed in low values of $\mathrm{Y}_{(\mathrm{NPQ}) 625}$ and high values of $\mathrm{Y}_{(\mathrm{NO}) 625}$.

Under drought conditions at the tillering stage, alloline D-d-05, which exceeded the others in terms of the totality of productivity-related parameters, showed a high photosynthetic capacity $\left(\mathrm{ETR}_{\max }\right)$. This line showed medium levels of studied parameters at further vegetation stages. Alloline D-d-05b, which showed a similar level of productivity, was characterized at the stages of subflag and flag leaves formation by the lowest values of nonorganized part of quantum yield of PSII (nonregulated quantum yield component) at PPFD of $65 \mu \mathrm{mol} \mathrm{m} \mathrm{m}^{-2} \mathrm{~s}^{-1}$. This parameter reflects mainly the level of closed PSII reaction centers. At the beginning of RLC, a low level of this parameter together with a high $\mathrm{Y}_{(\mathrm{II}) 65}$ can be considered as a marker of the absence of damages in PSII. These two genotypes, D-d-05 and D-d-05b, were marked by the highest value of leaf area of the upper tier and highest flag leaf to subflag area ratio. Furthermore, these parameters were significantly and positively correlated with the 1,000-grain mass.

Conclusion: The study showed relations between chlorophyll fluorescence-related parameters derived from RLCs and plant vegetation stages, sample genotype, and environmental conditions. At the early stages of cultivation, quantum yield parameters at the beginning of the rapid light curve $\left(\mathrm{Y}_{(\mathrm{II}) 65}, \mathrm{Y}_{(\mathrm{NO}) 65}, \mathrm{Y}_{(\mathrm{NPQ}) 65}\right)$, are recommended for the evaluation of productivity potential. At the stages of formation of subflag and flag leaf, parameters related to photosynthetic capacity $\left(\mathrm{ETR}_{\max }, \mathrm{E}_{\mathrm{k}}, \alpha\right)$ become more informative for this aim. For drought tolerance screening, $\mathrm{Y}_{(\mathrm{NO})}$ and $\mathrm{Y}_{(\mathrm{II}) 65}$ are particularly noteworthy.

Allolines D-d-05 and D-d-05b can be described as promising not only for the breeding program for drought 
tolerance but also as valuable varieties. Particularly, D-d-05 showed not only high stability of ChlFP during ontogenesis and high values of photosynthetic capacity under drought conditions, but also realized the full potential of grain productivity higher than that of the parent species.

\section{References}

Ali Q., Ashraf M.: Induction of drought tolerance in maize (Zea mays L.) due to exogenous application of trehalose: Growth, photosynthesis, water relations and oxidative defense mechanism. - J. Agron. Crop Sci. 197: 258-271, 2011.

Ashraf M., Harris P.J.C.: Photosynthesis under stressful environments: An overview. - Photosynthetica 51: 163-190, 2013.

Chaves M.M., Flexas J., Pinheiro C.: Photosynthesis under drought and salt stress: Regulation mechanisms from whole plant to cell. - Ann. Bot.-London 103: 551-560, 2009.

Cui Y., Tian Z., Hu J. et al.: Drought priming during the vegetation stage can enhance post-anthesis drought tolerance by improving photosynthetic capacity in winter wheat. - Arid Land Res. Manag. 33: 183-199, 2019.

Cui Y., Tian Z., Zhang X. et al.: Effect of water deficit during vegetation growth periods on post-anthesis photosynthetic capacity and grain yield in winter wheat (Triticum aestivum L.). - Acta Physiol. Plant. 37: 196, 2015.

Dalal V.K., Tripathy B.C.: Water-stress induced downsizing of light-harvesting antenna complex protects the developing rice seedlings from photo-oxidative damage. - Sci. Rep.-UK 8: 5955, 2018.

del Pozo A., Méndez-Espinoza A.M., Romero-Bravo S. et al.: Genotypic variations in leaf and whole-plant water use efficiencies are closely related in bread wheat genotypes under well-watered and water-limited conditions during grain filling. - Sci. Rep.-UK 10: 460, 2020.

El-Hendawy S.E., Ruan Y., Hu Y., Schmidhalter U.: Comparison of screening criteria for salt tolerance in wheat under field and controlled environmental conditions. - J. Agron. Crop Sci. 195: 356-367, 2009.

Fischer R.A., Edmeades G.O.: Breeding and cereal yield progress. - Crop Sci. 50: 85-98, 2010.

Flexas J., Bota J., Loreto F. et al.: Diffusive and metabolic limitations to photosynthesis under drought and salinity in $\mathrm{C}_{3}$ plants. - Plant Biol. 6: 269-279, 2004

Gahlaut V., Jaiswal V., Kumar A., Gupta P.K.: Transcription factors involved in drought tolerance and their possible role in developing drought tolerant cultivars with emphasis on wheat (Triticum aestivum L.). - Theor. Appl. Genet. 129: 2019-2042, 2016.

Giard M.T., Cona A., Geiken B. et al.: Long-term drought stress induces structural and functional reorganization of photosystem II. - Planta 199: 118-125, 1996.

Gupta N., Gupta S., Kumar A.: Water stress impacts physiological plant states and attributes their relationship with growth and yield of wheat cultivars at different stages. - J. Agron. Crop Sci. 186: 55-62, 2001.

He J.X., Wang J., Liang H.G.: Impacts of water stress on photochemical function and protein metabolism of photosystem II in wheat leaves. - Physiol. Plantarum 93: 771-777, 1995.

Inoue T., Inanaga S., Sugimoto Y., El Siddig S.: Contribution of pre-anthesis assimilates current photosynthesis to grain yield and their relationships to drought resistance in wheat cultivars grown under different levels of soil moisture. Photosynthetica 42: 99-104, 2004.
Klughammer C., Schreiber U.: Complementary PS II quantum yields calculated from simple fluorescence parameters were measured by PAM fluorometry and Saturation Pulse method. - PAM Appl. Notes 1: 27-35, 2008a.

Klughammer C., Schreiber U.: Saturation pulse method for assessment of energy conversion in PSI. - PAM Appl. Notes 1: 11-14, 2008b.

Lancashire P.D., Bleiholder H., van den Boom T. et al.: A uniform decimal code for growth stages of crops and weeds. - Ann. Appl. Biol. 119: 561-601, 1991.

Lawlor D.W., Tezara W.: Cause of decreased photosynthetic rate and metabolic capacity in water-deficient leaf cells: a critical evaluation of mechanisms and integration of processes. Ann. Bot.-London 103: 561-579, 2009.

Li W.-T., Park J.-I., Park S.R. et al.: Chlorophyll $a$ fluorescence as an indicator of establishment of Zostera marina transplants on the southern coast of Korea. - Algae 25: 89-97, 2010.

Miller G., Suzuki N., Ciftci-Yilmaz S., Mittler R.: Reactive oxygen species homeostasis and signaling during drought and salinity stresses. - Plant Cell Environ. 33: 453-467, 2010.

Mohammadi M., Karimizadeh R.A., Naghavi M.R.: Selection of bread wheat genotypes against heat and drought tolerance based on chlorophyll content and stem reserves. - J. Agric. Soc. Sci. 5: 119-122, 2009.

Pareek A., Sopory S.K., Bohnert H., Govindjee (ed): Abiotic Stress Adaptation in Plants: Physiological, Molecular and Genomic Foundation. Pp. 526. Springer, Dordrecht 2010.

Pradhan G.P., Prasad P.V.V., Fritz A.K. et al.: Effects of drought and high temperature stress on synthetic hexaploid wheat. Funct. Plant Biol. 39: 190-198, 2012.

Rajala A., Hakala K., Mäkelä P. et al.: Spring wheat response to timing of water deficiency it through sink and grain filling capacity. - Field Crop. Res. 114: 263-271, 2009.

Ralph P.J., Gademann R.: Rapid light curves: A powerful tool to assess photosynthetic activity. - Aquat. Bot. 82: 222-237, 2005.

Rascher U., Liebig M., Lüttge U.: Evaluation of instant lightresponse curves of chlorophyll fluorescence parameters obtained with a portable chlorophyll fluorometer on site in the field. - Plant Cell Environ. 23: 1397-1405, 2000.

Saqib M., Akhtar J., Abbas G. et al.: Salinity and drought interaction in wheat (Triticum aestivum L.) is affected by the genotype and plant growth stage. - Acta Physiol. Plant. 35: 2761-2768, 2013.

Schöttler M.A., Kirchhoff H., Weis E.: The role of plastocyanin in the adjustment of photosynthetic electron transport to the carbon metabolism in tobacco. - Plant Physiol. 136: 42654274, 2004.

Stupko V.Yu., Zobova N.V., Sidorov A.V., Gaevskii N.A.: [Promising methods for assessing spring common wheat for sensitivity to edaphic stress.] - Dostizheniya nauki i tekhniki APK. 33: 45-50, 2019. [In Russian] doi: 10.24411/02352451-2019-11010.

Terletskaya N.V., Khailenko N.A., Mamonov L.K.: Teratological changes generative various of wheat in a weak chloride salinity. - Annu. Res. Rev. Biol. 4: 1230-1240, 2014.

Terletskaya N.V., Lee T.E., Altayeva N.A. et al.: Some mechanisms modulating root growth of various wheat species under osmotic-stress conditions. - Plants-Basel 9: 1545 , 2020a.

Terletskaya N.V., Shcherban A.B., Nesterov M.A. et al.: Drought stress tolerance and photosynthetic activity of alloplasmic lines $T$. dicoccum $\times$ T. aestivum. - Int. J. Mol. Sci. 21: 3356, 2020 b.

Terletskaya N.V., Zobova N., Stupko V. et al.: Growth and photosynthetic reactions of different species of wheat 
seedlings under drought and salt stress. - Period. Biol. 119: 37-45, 2017.

Tripathy B.C., Mohapatra A., Gupta I.: Impairment of the photosynthetic apparatus by oxidative stress induced by photosensitization reaction of protoporphyrin IX.
BBA-Bioenergetics 1767: 860-868, 2007.

Zhao M.S., Running S.W.: Drought-induced reduction in global terrestrial net primary production from 2000 through 2009 . Science 329: 940-943, 2009.

(C) The authors. This is an open access article distributed under the terms of the Creative Commons BY-NC-ND Licence. 